\section{Nursing \\ PMO-001 THE ROLE OF THE SPECIALIST SCREENING PRACTITIONER WITHIN THE BOWEL SCREENING WALES PROGRAMME}

doi:10.1136/gutjnl-2012-302514b.1

R Kyte.* Endoscopy Unit, Ysbyty Ystrad Fawr, Aneurin Bevan Health Board, Ystrad Mynach, UK

Introduction Bowel Screening Wales (BSW) was launched nationally in October 2008. With its launch came the introduction of a unique, autonomous nursing role which is placed at the interface of secondary and primary care.

Methods Specialist Screening Practitioners (SSPs) are based at all BSW Local Assessment Centres (LACs) throughout Wales. The original sixteen SSPs employed prior to the inception of the BSW programme had diverse clinical backgrounds and all underwent a 4-week induction programme. On returning to their local areas, SSPs were supported by a programme of clinical induction which incorporated an understanding of agreed competencies. During the initial induction phase SSPs were mentored by the Regional Nurses and Lead Screening Colonoscopists. The role of the SSP is multi faceted. They apply advanced expert clinical knowledge and experience alongside evidence based decision making skills to support participants who have received a positive faecal occult blood test and have consented to speak to a SSP. Each practitioner has their own participant caseload for which they are accountable. They assess participants' fitness to undergo a colonoscopy, arrange the colonoscopy, consent the participants prior to the colonoscopy and are present during the colonoscopy. They also give results, ensure that the participants are placed on the routine recall or surveillance pathway, refer to and attend Multi Disciplinary Team meetings following a participant's diagnosis of cancer. Many participants require considerable support from their SSP due to their medical history which may include mental health issues, the presence of comorbidity and social problems. As the role of SSP is an advanced nursing role all practitioners are required to posses or be working towards a Degree. BSW has collaborated with Cardiff University to develop a MSc module. All Wales SSP network meetings are held twice per year and offer educational and peer support. SSPs employed since the autumn of 2008 undergo a programme of induction based on their educational needs.

Results As a result of the support given by SSPs, participants are well informed about the procedure. Compliance with bowel preparation is high as is evidenced by the low numbers of incomplete colonoscopy. There is a very low rate of participants who do not attend for colonoscopy.

Conclusion Over the last 3 years the role of the SSP has continually evolved. The role can be further developed by sharing knowledge and good practice on a UK wide basis.

Competing interests None declared.

\section{Service development I}

\section{PM0-002 EVALUATION OF A NURSE AND DIETETIC LED FOLLOW- UP SERVICE FOR PATIENTS WITH AN UPPER GASTROINTESTINAL MALGNANCY}

doi:10.1136/gutjnl-2012-302514b.2

A Procter, ${ }^{*}$ T Wilccocks, A Fletcher. Department of Surgery, Bradford Teaching Hospitals NHS Foundation Trust, Bradford, UK

Introduction The Clinical Nurse Specialist Team developed a nurse and dietetic led follow-up service. Is the service effective and does it meet patient's needs?
Methods The team devised a questionnaire for both the patients and the clinicians. All patients who had attended the clinic and the three surgical consultants were sent questionnaires. Exclusions were duplicates and those deceased. A total of 100 patient and three clinician questionnaires were sent. The patients and clinicians were asked to return the questionnaires to a Clinical Governance support officer who collated the results. In total the team received 89 responses from patients and two from clinicians equating to a $74 \%$ return rate.

Results The majority of patients responded favourably to the nurse and dietetic led service, with only $2 \%$ of respondents preferring a consultant led service. Neither of the responding clinicians felt that the service needed to change. $80 \%$ of respondents felt the length of their appointment was adequate. The majority of patients responded favourably to the nurse and dietetic led service, with only $2 \%$ of respondents preferring a consultant led service. Neither of the responding clinicians felt that the service needed to change. $80 \%$ of respondents felt the length of their appointment was adequate.

Conclusion One follow-up clinic per week has streamlined the workload ensuring an equitable, appropriate service. It has also supported the continued professional development of the CNS team/Dietetic team and a more productive workforce. This has highlighted the value of the role of the CNS and Dietetic Team. The Nurse and Dietetic Led service provides the opportunity for patients to have a longer, in depth consultation meeting the recommendations of the Supportive and Palliative Care Guidance Holistic Needs Assessment.

Competing interests None declared.

\section{REFERENCES}

1. The Department of Health. A Policy Framework for Commissioning Cancer Services A Report By The Expert Advisory Group On Cancer To The Chief Medical Officers of England and Wales. London. 1995.

2. The Department of Health. The NHS Cancer Plan. A Plan For Investment. A Plan For Reform. London. 2000.

3. The Department of Health. National Surveys of NHS patients: Cancer National Overview 1999-2000. London. 2002.

4. The Department of Health. Cancer Reform Strategy. London. 2007.

5. The Department of Health. National Cancer Survivorship Initiative. London. 2008.

6. National Institute for Clinical Excellence. Improving Supportive and Palliative Care For Adults. London. 2004.

\section{PMO-003 EFFECT OF MRI AND VARIABLE STIFFNESS COLONOSCOPES ON CAECAL INTUBATION RATES BY EXPERIENCED ENDOSCOPISTS}

doi:10.1136/gutjnl-2012-302514b.3

A Terlevich,* J Maltby, J Linehan. Department of Gastroenterology, Royal United Hospital bath, Bath, UK

Introduction Magnetic endoscopic imager (MEI) and variable stiffness colonoscopes (VSC) have been shown to improve caecal intubation rates in trainees. Many trained endoscopists in our department prefer to perform colonoscopies with them rather than without. The aim of this study was to assess colonoscopic performance data in experienced endoscopists, with and without the use of MEI and VSC, in our endoscopy department.

Methods Our endoscopy department uses Olympus VSC with MEI in two theatres and standard Pentax colonoscopes with no variation in stiffness or 3D imaging, in our two other theatres. All equipment was purchased in 2009. Experienced endoscopists use both Olympus and Pentax equipment. We have conducted a retrospective case note analysis to assess caecal intubation rates, terminal Ileum intubation rates, polyp detection rates and sedation used, by individual endoscopists.

Results We reviewed 3984 procedures, performed by 16 experienced endoscopists between September 2009 and November 2011. 2598 colonoscopies used Olympus VSC with MEI and 1386 with Pentax equipment. Caecal intubation rate (CIR) was higher in 13/16 